\title{
EFEITO DO USO DE INOCULANTES SOBRE O pH E A COMPOSIÇÃO BROMATOLÓGICA DA SILAGEM DE SORGO (Sorghum bicolor L. Moench)
}

\author{
(Effect of bacterial inoculant on $\mathrm{pH}$ and bromatological composition of \\ sorghum silage (Sorghum bicolor L. Moench)
}

\author{
GRISE, M.M. ${ }^{1}$; MARTINS, R.L.. ${ }^{1}$ FERNANDES, A.C. ${ }^{\text {; }}$ ROSSI JUNIOR, P. ${ }^{2}$ PIAZZETTA, R.G. ${ }^{3}$ \\ 'Engenheiro Agrônomo, Curitiba-PR; \\ ${ }^{2}$ Departamento de Zootecnia UFPR, Curitiba-PR; \\ ${ }^{3}$ Médico Veterinário, Mestrando Curso de Ciências Veterinárias UFPR.
}

\begin{abstract}
RESUMO - O objetivo do presente trabalho foi estudar o efeito de três doses do aditivo bacteriano comercial Sil-All $\left(\right.$ Alltech $\left.^{\circledR}\right)$, sobre o pH e a composição bromatológica da silagem de sorgo, variedade AG 2005. Foram utilizados 16 silos experimentais, com capacidade para $20 \mathrm{~kg}$ de silagem. Os tratamentos testados foram T1: sem a adição de inoculante, T2: 2,5g/L de inoculante, T3: $5,0 \mathrm{~g} / \mathrm{L}$ de inoculante e T4: $7,5 \mathrm{~g} / \mathrm{L}$ de inoculante. Após 60 dias de ensilado, os silos foram abertos e retiradas amostras para determinação de $\mathrm{pH}, \mathrm{PB}, \mathrm{FDN}$ e FDA. O delineamento foi inteiramente casualizado, com quatro tratamentos e quatro repetições. As diferentes doses aplicadas resultaram em diferença significativa $(P<0,05)$ para o teor de $M S$, sendo inferior para o tratamento sem inoculante (T1). A presença de inoculante nas silagens não afetou significativamente $(\mathrm{P}>0,05)$ os teores de $\mathrm{pH}, \mathrm{PB}, \mathrm{FDN}$ e FDA.
\end{abstract}

Palavras-chave: aditivos bacterianos; matéria seca; qualidade de silagem; proteina bruta.

\begin{abstract}
The objective of this work was to study the effect of three doses of commercial bacterial inoculant Sil-All $\left(\right.$ Alltech $\left.{ }^{\circledR}\right)$, on the $\mathrm{pH}$ and the quality of the silage of sorgo, variety AG 2005. Sixteen experimental silos had been used, with capacity for $20 \mathrm{~kg}$ of silage. The tested treatments had been $\mathrm{T} 1$ without the inoculante addition, T2: $2,5 \mathrm{~g} / \mathrm{L}$ of inoculante, $\mathrm{T} 3: 5,0 \mathrm{~g} / \mathrm{L}$ of inoculante and T4: $7,5 \mathrm{~g} / \mathrm{L}$ of inoculante. After 60 days, the silos had been opened and samples removed for determination of $\mathrm{pH}$, PB, FDN and FDA. The delineation was completely randomized, with four treatments and four repetitions. The different applied doses had resulted in significant difference $(P<0,05)$ for the MS content, being inferior for the treatment without inoculante (T1). The presence of inoculant in the silages had not significantly affected $(P>0,05)$ values of $\mathrm{pH}, \mathrm{PB}, \mathrm{FDN}$ and FDA.
\end{abstract}

Key-words: bacterial inoculant; crude protein; dry matter; quality of silage.

\section{Introdução}

O sorgo é uma gramínea anual de verão, com ciclo de 90 a 100 dias e colmos eretos, podendo atingir 2,5 a 4,0 m de altura. É uma planta rústica, mais resistente a seca que o milho, que possui em torno de $11,5 \%$ de PB.

A cultura do sorgo contribui com 10 a $12 \%$ da área total cultivada para silagem no Brasil e se destaca, de modo geral, por apresentar produtividade de matéria seca (ton MS/ha/ano) mais elevada que a do milho, principalmente em condições de cultivo em solos de baixa fertilidade natural e em locais onde é freqüente a ocorrência de estiagens longas (ROCHA JÚNIOR et al., 2000).

A utilização de silagem como volumoso é uma prática muito difundida. Entre as espécies forrageiras que podem ser ensiladas, o sorgo (Sorghum bicolor, L. Moench) destaca-se por ser um alimento com concentração de carboidratos solúveis adequada para uma boa fermentação láctica, como também pelo seu alto valor nutritivo e altos rendimentos de matéria seca por unidade de área (SILVA e RESTLE, 1993).

O valor nutritivo do sorgo ensilado depende, entre outros, de três fatores principais: do híbrido utilizado, observando altura da planta, produtividade, produção de grãos, tolerância à seca e resistência às doenças; do estádio em que o mesmo foi cortado, que influencia a composição e a qualidade final do material conservado, sendo a fase ideal para a ensilagem entre os estádios pastoso e leitoso (planta já crescida com cerca de $30 \%$ de matéria seca) e dos microrganismos nele presentes durante o processo de ensilagem (WEBSTER, 1962; CUMMINS, 1971).

Segundo WOOLFORD (1990) existem três características principais que interferem no processo de ensilagem: teor de umidade, capacidade tamponante e teor de carboidratos solúveis. Esses fatores podem afetar negativamente o processo fermentativo, impedindo o rápido decréscimo do $\mathrm{pH}$ pela alta capacidade tamponante ou pela própria falta de substratos fermentescíveis para que haja fermentação láctica.

Aditivos vêm sendo utilizados em pesquisas. De modo geral os inoculantes compostos por culturas de bactérias produtoras de ácido láctico deveriam ter capacidade comprovada para redução de perdas de matéria seca, aumento da qualidade higiênica, limitação de fermentações secundárias, aumento da estabilidade

Autor para correspondência: Paulo Rossi Junior - Fone: (41) 3350-5705 - E-mail: parossi@ufpr.br. 
aeróbia e do valor nutritivo da silagem (HENDERSON, 1993).

De acordo com BOLSEN et al. (1995), a inoculação de bactérias produtoras de ácido láctico na forragem a ser ensilada pode favorecer a fermentação, resultando em queda mais rápida e manutenção de $\mathrm{pH}$ baixo, um aumento na relação entre ácido láctico e acético e diminuição dos teores de nitrogênio amoniacal.

No entanto, HARRISON e BLAUWIEKEL (1994) discutem que os efeitos do uso de aditivos microbianos estão condicionados ao tipo de inoculante e sua atividade biológica, à quantidade aplicada e ao tipo de forragem em conteúdo de matéria seca e composição química.

Segundo ASHBELL (1995), inoculantes utilizados em determinadas regiões com sucesso podem não ser eficientes em outras, indicando que há influência das condições do local sobre o efeito do inoculante na silagem.

O objetivo foi determinar os efeitos de 3 doses do inoculante microbiano Sil-All $\left(\right.$ Alltech ${ }^{\circledR}$ ) sobre o $\mathrm{pH}$ e a composição bromatológica do sorgo AG 2005 ensilado.

\section{Material e Métodos}

O experimento foi conduzido no Centro de Estações Experimentais do Canguiri, pertencente à Universidade Federal do Paraná, em solo classificado como Cambissolo Álico (SECRETARIA DO ESTADO DO PARANÁ, 1985).

O sorgo foi plantado em janeiro de 2001. Antes do plantio foi realizada a calagem e adubação da área. A adubação consistiu em $200 \mathrm{~kg} / \mathrm{ha}$ de $10-16-16$ e uma adubação de cobertura com $250 \mathrm{~kg} / \mathrm{ha}$ de $45-00-00$. O corte foi realizado com 100 dias após o plantio, quando os grãos apresentavam-se em estado pastoso à farináceo.

Como silos experimentais, foram utilizados 16 tubos de PVC com capacidade para 18,0L. Foram acondicionados $20 \mathrm{~kg}$ de sorgo triturado ao tamanho médio de partícula de $1,5 \mathrm{~cm}$, compactados com soquete de madeira. Os silos não possuíam camada para absorção de efluentes nem válvula para liberação de gases. Foram adicionados de uma alíquota de 40 $\mathrm{mL}$ de inoculante, nas diluições testadas de acordo com os tratamentos. O material permaneceu sob anaerobiose por 60 dias.

O inoculante utilizado foi o Sil-All $\left(\right.$ Alltech $\left.{ }^{\circledR}\right)$ (Streptococcus faecium, Pediococcus acidilactici, Lactobacillus plantarum, amilase, hemicelulase e celulase), preparado conforme a recomendação do fabricante. Os tratamentos consistiram de silagem sem uso de inoculante (T1), silagem com $2,5 \mathrm{~g} / \mathrm{L}$ de inoculante (T2) $(1 / 2$ dose recomendada), silagem com $5,0 \mathrm{~g} / \mathrm{L}$ de inoculante (T3) (dose recomendada) e silagem com 7,5 g/L de inoculante (T4) (1,5 dose recomendada).

Após a abertura dos silos experimentais, determinouse $0 \mathrm{pH}$ no extrato da silagem, obtido em prensa, desenvolvida para este trabalho. Amostras foram levadas à estufa de circulação forçada de ar à 55ㄷ por 72 horas, para secagem do material e para determinação da matéria seca (MS). Os teores de proteína bruta (PB), fibra em detergente neutro (FDN) e fibra em detergente ácido (FDA) foram obtidas através de análise por infravermelho (NIRs).

O delineamento experimental foi inteiramente casualizado com quatro tratamentos e quatro repetições. Foi utilizado o teste de Duncan $(P=0,05)$ para comparação das médias.

\section{Resultados e Discussão}

Os dados de $\mathrm{pH}, \mathrm{MS}, \mathrm{PB}, \mathrm{FDN}$ e FDA das silagens são apresentados na TABELA 1. Não houve diferença significativa $(P>0,05)$ entre o material não inoculado e o inoculado com diferentes doses quanto ao $\mathrm{pH}, \mathrm{PB}$, FDN e FDA.

TABELA 1 - TEORES DE pH, MATÉRIA SECA (MS), PROTEÍNA BRUTA (PB), FIBRA EM DETERGENTE NEUTRO (FDN) E FIBRA EM DETERGENTE ÁCIDO (FDA) DA SILAGEM DE SORGO (AG 2005), USANDO DIFERENTES DOSES DE ADITIVO SIL-ALL (ALLTECH $\left.{ }^{\circledR}\right)$.

\begin{tabular}{cccccc}
\hline Parâmetros & $\begin{array}{c}\text { Sem } \\
\text { Aditivo }\end{array}$ & $\begin{array}{c}50 \% \text { da dose } \\
\text { recomendada }\end{array}$ & $\begin{array}{c}\text { Dose } \\
\text { recomendada }\end{array}$ & $\begin{array}{c}50 \% \text { superior a dose } \\
\text { recomendada }\end{array}$ & $\begin{array}{c}\text { CV } \\
(\%)\end{array}$ \\
\hline pH & 3,89 & 3,87 & 3,87 & 3,83 & 1,42 \\
MS (\%) & $19,8 b$ & $23,7 \mathrm{a}$ & $22,6 \mathrm{a}$ & $21,7 \mathrm{a}$ & 5,05 \\
PB (\%) & 8,05 & 7,83 & 7,50 & 8,33 & 9,63 \\
FDN (\%) & 68,88 & 66,43 & 71,08 & 68,20 & 6,10 \\
FDA (\%) & 44,95 & 44,30 & 45,78 & 44,05 & 4,39 \\
\hline
\end{tabular}

Letras diferentes, nas linhas, diferem entre si $\mathrm{P}<0,05$, pelo teste de Duncan.

Os dados obtidos no presente experimento discordam dos obtidos por MEESKE et al. (1983) e SANDERSON (1993), os quais observaram aumento na produção de ácido láctico e mais rápida redução no $\mathrm{pH}$ nas silagens de sorgo tratadas com inoculantes enzimomicrobianos ou microbianos, respectivamente, quando comparadas às silagens controles, mas concordam com os dados de experimentos realizados por PEDROSO et al. (2000) e RODRIGUES et al. (2002), os quais não observaram efeitos dos inoculantes microbianos sobre o perfil fermentativo (concentração de ácidos orgânicos) e o pH da silagem desta forrageira.

$\mathrm{O} \mathrm{pH}$ ideal de silagens bem conservadas está entre 3,8 e 4,2. Entretanto, o pH isoladamente não deve ser 
Efeito do uso de inoculantes sobre o ph e a composição bromatológica da silagem de sorgo...

considerado como um critério de qualidade fermentativa, já que seu efeito inibitório sobre as bactérias depende da rapidez com que ocorre o declínio o $\mathrm{pH}$ e da umidade do meio. No presente estudo, as silagens tiveram os valores de $\mathrm{pH}$ muito próximos e na faixa considerada de boa fermentação.

A matéria seca (MS) mostrou-se maior $(P<0,05)$ nos tratamentos com o uso de inoculante. O mesmo resultado foi obtido por PEDROSO et al. (2000) avaliando a ensilagem de sorgo com inoculante bacteriano.

Porém, RODRIGUES et al. (2002) observaram que a inoculação bacteriana em silagem de sorgo proporcionou menores teores de matéria seca na mesma. Esse efeito foi explicado pelos autores como uma conseqüência da maior quantidade de compostos voláteis (etanol e outros) produzidos pelas silagens inoculadas, sendo que esses compostos teriam se perdido durante a avaliação da matéria seca e subestimado tais valores. Outra justificativa seria a afirmação de ZAGO (1991) que as modificações no processo fermentativo do sorgo poderiam reduzir o teor de MS devido à produção de "água de metabolismo".

Os valores de FDN refletem a conservação dos materiais solúveis da silagem. No presente estudo, os valores de FDN não apresentaram diferença significativa $(P>0,05)$ entre os diferentes tratamentos. Estudos conduzidos por RODRIGUES et al. (2002) avaliando diferentes inoculantes comerciais observaram que 0 produto Sil-All diferiu $(P<0,05)$ do grupo controle quanto ao teor de FDN, aumentando seu valor em 4,5\% (2,6 unidades percentuais). Porém, para FDA e PB os valores obtidos pelos autores não diferiram com o uso do mesmo produto.

PEDROSO et al. (2000) observaram que a silagem tratada com inoculante mostrou níveis mais elevados ( $\mathrm{P}<$ $0,05)$ de FDN $(41,28$ e $39,14 \%$ da MS) e FDA $(24,89$ e $22,53 \%$ da $M S$ ), evidenciando maior perda de material solúvel, porém não diferiu quanto ao teor de PB (7,93 e 7,99\% da MS) e energia bruta (EB) $(4,46$ e 4,44 kcal/g da MS), em relação ao controle. Segundo RODRIGUES et al. (2001) o uso de inoculantes em silagem de milho e sorgo no Brasil, não mostrou até o momento efeitos significativos sobre o valor nutritivo de tais forrageiras.

Estes resultados são contrastantes aos obtidos por WEINBERG et al. (1993), que não observaram efeito do inoculante sobre os parâmetros nutricionais da silagem de sorgo, o que confirma as observações de RODRIGUES et al. (2001), ROCHA et al. (2003), SEMMELMANN et al. (2004) e VIEIRA et al. (2004) de que o uso de aditivos microbianos em silagens de milho e de sorgo não proporcionaram aumento significativos sobre o valor nutricional das mesmas.

\section{Conclusão}

O uso de inoculantes microbianos não afetou a composição bromatológica e o pH da silagem de sorgo, apesar da modificação nos teores de MS observados neste trabalho. Mais estudos são necessários para investigar os efeitos do inoculante microbiano testado sobre a silagem de sorgo.

\section{Referências}

ASHBELL, G. Basic principles of preservation of forage, by-products and residues as silage or hay. Bet Dagan: Agricultural Research Organization, The Volcani Center. (n.1664-E). 58p, 1995.

BOLSEN, K.K.; ASHBELL, G.; WILKINSON, J.M. Silage additives. In: WALLACE, J., CHESSON, A. (Ed.) Biotechnology in animal feeds and animal feeding. New York: VCH Weinheim. p.33-54, 1995.

CUMMINS, D.G. Relationships betweem tannin content and forage digestibility in sorghum. Agronomy Journal, v.63, n.2, p.500-502, 1971.

HARRISON, J.H.; BLAUWIEKEL, R. Fermentation and utilization of grass silage. Journal of Dairy Science, v.77, n.10, p.3209-3235, 1994.

HENDERSON, N. Silage additives. Animal Feed Science and Technology, v.45, n.1, p.35-56, 1993.

MEESKE, R.; ASHBELL, G.; WEINBERG, Z.G. Ensiling forage sorghum at two stages of maturity with the addition of latic acid bacterial inoculants. Animal Feed Science and Technology, v.43, n.1, p.165-175, 1983.

PEDROSO, A.F.; FREITAS, A.R.; SOUZA, G.B. Efeito de inoculante bacteriano sobre a qualidade da silagem $e$ perda de matéria seca durante a ensilagem de sorgo. Revista Brasileira de Zootecnia, Viçosa - MG, v.29, n.1, p.48-52, 2000.

ROCHA JÚNIOR, V. R.; GONÇALVES, L.C.; RODRIGUES, J.A.S.; BRITO, A.F.; RODRIGUEZ, N.M.; BORGES, I. Avaliação de sete genótipos de sorgo (Sorghum bicolor (L.) Moench) para produção de silagem: I. Características agronômicas. Arquivo Brasileiro de Medicina Veterinária e Zootecnia, v.52, p.506-511, 2000.

ROCHA, K.D.; PEREIRA, O.G.; GARCIA, R. Consumo e digestibilidade de silagens de sorgo tratadas com inoculantes bacterianos. In: REUNIÃO ANULA DA SOCIEDADE BRASILEIRADE ZOOTECNIA, 40, 2003, Santa Maria. Anais... Santa Maria: SBZ/UFSM, 2003, CD-ROM.

RODRIGUES, P.H.M.; ANDRADE, S.J.T.; RUZANTE, L.M.; LIMA, F.R.; MELOTTI, L. Valor nutritivo de silagens inoculadas com bactérias ácido-láticas. 1. Inoculação da silagem de milho. In: REUNIÃO ANUAL DA SOCIEDADE BRASILEIRA DE ZOOTECNIA, 38, 2001, Piracicaba. Anais... Piracicaba:FEALQ, 2001, p.920-21.

RODRIGUES, P.H.M.; SENATORE, A.L.; ANDRADE, S.J.T.; RUZANTE, J.M.; LUCCI,C.S.; LIMA, F.R. Efeitos da adição de inoculantes microbianos sobre a composição bromatológica e perfil fermentativo da silagem de sorgo produzida em silos experimentais. Revista Brasileira de Zootecnia, v.31, n.6, p.2373-2379, 2002. 
SANDERSON, M.A. Aerobic stability and in vitro fiber digestibility of microbially inoculated corn and sorghum silages. Journal of Animal Science, v.71, n.2, p.505514, 1993.

SECRETARIA DO ESTADO DO PARANÁ. Mapeamento dos municípios do Estado do Paraná, Curitiba, 1985, $341 \mathrm{p}$.

SEMMELMANN, C.E.N.; GOMES, I.P.O.; NETO, A.T.; SANTANA, T.; JORGE, L. Avaliação da qualidade de silagens de milho e sorgo submetidas a adição de inoculantes bacterianos. In: REUNIÃO ANUAL DA SOCIEDADE BRASILEIRA DE ZOOTECNIA, 41, 2004, Campo Grande. Anais... Campo Grande:UFMS, 2004, CD-ROM.

SILVA, L. C. R.; RESTLE, J. Avaliação do milho (Zea mays L.) e do sorgo (Sorghum bicolor L. Moench) para produção de silagem. In: REUNIÃO ANUAL DA SOCIEDADE BRASILEIRA DE ZOOTECNIA, 30, 1993, Rio de Janeiro. Anais... Rio de Janeiro, 1993, p. 467.
VIEIRA, F.A.P.; BORGES, I.; STEHLING, C.A.V.; GONÇALVES, L.C.; COELHO, S.G.; FERREIRA, M.I.C.; RODRIGUES, J.A.S. Quality of sorghum silages with additives. Arquivo Brasileiro de Medicina Veterinária e Zootecnia, v. 56, n. 6, p. 764-772, 2004.

WEBSTER, O.J. Effect of harvest dates on forage sorghum yields porcentage of dry-mater, protein and soluble solids. Agronomy Journal, v.55, n.7, p.17401747, 1962.

WEINBERG, Z.G.; ASHBELL, G.; HEN, Y. The effect of applying lactic acid bacteria at ensiling on aerobic stability of silages. Journal Applied Bacteriology, v.75, n.6, p.512-518, 1993.

WOOLFORD, M.K. A review: The detrimental effects of air on silage. Journal Applied Bacteriology, v.68, p.101-116, 1990. ZAGO, C.P. Cultura de sorgo para a produção de silagem de alto valor nutritivo. In: SIMPÓSIO SOBRE NUTRIÇÃO DE BOVINOS, 4, 1991, Piracicaba. Anais... Piracicaba: Fundação de Estudos Agrários Luiz de Queiroz, 1991. p.169-213.

Recebido para publicação: $\quad 30 / 11 / 2005$ Aprovado: 